\title{
Malignant Pleural Effusion: Diagnosis and Management
}

\author{
Lucía Ferreiro $\mathbb{D}^{1,2}$ Juan Suárez-Antelo, ${ }^{1}$ José Manuel Álvarez-Dobaño, ${ }^{1,2}$ \\ María E. Toubes, ${ }^{1}$ Vanessa Riveiro, ${ }^{1}$ and Luis Valdés ${ }^{1,2}$ \\ ${ }^{1}$ Pulmonology Department, University Clinical Hospital of Santiago, Santiago de Compostela, Spain \\ ${ }^{2}$ Interdisciplinary Research Group in Pulmonology, Health Research Institute of Santiago de Compostela (IDIS), \\ Santiago de Compostela, Spain
}

Correspondence should be addressed to Lucía Ferreiro; lferfer7@gmail.com

Received 22 May 2020; Revised 5 July 2020; Accepted 11 September 2020; Published 23 September 2020

Academic Editor: Fulvio Braido

Copyright @ 2020 Lucía Ferreiro et al. This is an open access article distributed under the Creative Commons Attribution License, which permits unrestricted use, distribution, and reproduction in any medium, provided the original work is properly cited.

Symptomatic malignant pleural effusion is a common clinical problem. This condition is associated with very high mortality, with life expectancy ranging from 3 to 12 months. Studies are contributing evidence on an increasing number of therapeutic options (therapeutic thoracentesis, thoracoscopic pleurodesis or thoracic drainage, indwelling pleural catheter, surgery, or a combination of these therapies). Despite the availability of therapies, the management of malignant pleural effusion is challenging and is mainly focused on the relief of symptoms. The therapy to be administered needs to be designed on a case-by-case basis considering patient's preferences, life expectancy, tumour type, presence of a trapped lung, resources available, and experience of the treating team. At present, the management of malignant pleural effusion has evolved towards less invasive approaches based on ambulatory care. This approach spares the patient the discomfort caused by more invasive interventions and reduces the economic burden of the disease. A review was performed of the diagnosis and the different approaches to the management of malignant pleural effusion, with special emphasis on their indications, usefulness, cost-effectiveness, and complications. Further research is needed to shed light on the current matters of controversy and help establish a standardized, more effective management of this clinical problem.

\section{Introduction}

Malignant pleural effusion (MPE) is the second most frequent cause of pleural exudate [1]. The presence of malignant cells in the pleural fluid (PF) and/or pleural tissue confirms the presence of disseminated or advanced cancer and is associated with a lower life expectancy. According to a recent study, the survival of lung cancer patients with MPE is 5.5 months [2], whereas overall survival for all types of cancer ranged from 3 to 12 months, based on the type of tumour and comorbidities of the patient [3]. MPE affects $15 \%$ of oncologic patients [4]. As many as 50,000 and 150,000 new cases of MPE are diagnosed in UK [5] and USA [6] every year, with hospitalization costs amounting to more than five billion dollars [7]. Most MPE are symptomatic and frequently cause dyspnea, which is not only associated with the size of the PE, but also associated with the rate of fluid accumulation and the presence of underlying cardio- respiratory comorbidities. Other symptoms include chest pain, dry cough, or early feeling of satiety due to the pressure exerted by the PE on the stomach [3].

The management of MPE is merely palliative and should focus on the relief of symptoms. Therefore, recurrent invasive procedures should be avoided [8]. A recent study demonstrated that definitive pleural procedures (pleurodesis, indwelling pleural catheter (IPC), or both) compared to repeat thoracentesis resulted in fewer subsequent pleural procedures, fewer pneumothoraxes, and fewer Emergency Department procedures [8]. In the same line, avoidance of hospitalization and prevention of complications are recommended [9]. Individual patient's preferences should also be considered, together with comorbidities, recurrent PEs, the presence of loculations or a trapped lung, the features of the tumour, or the type of cancer [10].

Recent relevant studies [11, 12] have expanded the traditional portfolio of treatments for MPE $[3,5]$ and have 
led to the updating of clinical practice guidelines $[1,13,14]$. The purpose of this study was to review the current evidence on the management of patients with an MPE in order to provide an updated view of the progress made in recent years.

\section{Diagnostic Tests}

2.1. Imaging Tests. A suspicion of PE can be radiographically confirmed at a volume of $200 \mathrm{~mL}$. In addition, chest X-ray can detect as little as $50 \mathrm{~mL}$ of PF on a lateral view, which will show a costophrenic angle effusion [15]. A massive, loculated $\mathrm{PE}$ and a reduced volume of the ipsilateral lung are also suggestive of MPE. A retrospective study of more than 62,000 thoracocenteses for all-cause PE showed that chest ultrasound reduced the risk for pneumothorax by $19 \%$ $(\mathrm{OR}=0.81 ; 95 \% \mathrm{CI}=0.74-0.90)$ [16]. Therefore, it is recommended that thoracic ultrasound, which has no associated complications, is performed prior to thoracentesis. Thoracic ultrasound can also suggest an MPE based on the finding of pleural thickening $(>1 \mathrm{~cm})$, diaphragmatic nodules or diaphragmatic thickening $>7 \mathrm{~mm}$, visceral pleura thickening, or pleural irregularity/nodularity [17].

Computerized tomography (CT) has high specificity but low sensitivity to separate benign PE from MPE, and mesothelioma from pleural metastasis [18]. In a recent study involving 370 patients, 211 (57\%) had an MPE. CT identified 144 malignant PEs (sensitivity 68\%; CI 95\%: 62-75\%). Of the 159 benign PEs, CT correctly classified 124 as benign (specificity 78\%; CI 95\%: 72-84\%). The positive and negative predictive value of CT to identify MPE were $80 \%$ (CI 95\%: 75-86\%) and 65\%, respectively (CI 95\%: 58-72\%). This means that one in three patients suspected to have an MPE will have it despite a negative CT scan [19].

To date, there is limited evidence on the usefulness of positron emission tomography (PET) to identify an MPE in routine clinical practice $[20,21]$. This recommendation is based on the results of a recent meta-analysis involving 407 patients with an MPE and 232 patients with other types of effusions. This study yielded a moderate sensitivity and specificity for the diagnosis of malignancy ( $82 \%$ and $74 \%$, respectively), as PET imaging will incorrectly miss disease in early stage tumours and incorrectly classify malignancy in conditions such as inflammatory pleuritis [20].

The role of PET-CT in MPE is still unclear. The results of the TARGET trial (ISRCTN14024829), aimed at assessing the diagnostic yield of PET-CT-guided pleural biopsy versus CT-guided pleural biopsy on suspicion of MPE, will shed some light on this issue [22].

Magnetic resonance (MR) offers better-quality images of soft tissue than CT scans. Therefore, MR has higher sensitivity to detect chest-wall and diaphragmatic involvement, although the lung images have a lower quality [23]. Although there are reports of sensitivity and specificity rates of $90 \%$ to differentiate malignant from benign PE, the optimal protocol has not yet been established. This added to limited access to MR in some centers has excluded MR from standard diagnostic tests for MPE.
2.2. Cytology of Pleural Fluid. Cytology is the initial test in establishing a diagnosis of MPE. The diagnostic performance of cytology is close to $60 \%$ [24], with very low sensitivity for mesothelioma (6\%) and high for adenocarcinomas (79\%) [25]. In a recent retrospective study involving 725 patients with a solid neoplasm and suspected pleural metastasis, PF cytology had a diagnostic performance of $63 \%$. However, sensitivity varied according to the type of tumour and was lower for head and neck tumours and sarcomas (38\% for the two types) and renal tumours (53\%) and higher for breast (93\%) and pancreatic cancer (100\%) [26]. There are contradictory data on whether a high PF volume (>50-60 cc) can increase the diagnostic performance of cytology [27, 28]. However, it seems that a volume of $20-40 \mathrm{cc}$ would be enough to optimize the yield [24]. The low diagnostic performance of this procedure is due to the fact that the tumour is not always located in the surface of mesothelial cells, where malignant cells will be exfoliated in PF, but they may also involve the layer below the serous layer; therefore, only a few malignant cells will reach the pleural space.

Immunohistochemistry can help differentiate reactive mesothelial cells from those of malignant pleural mesothelioma and adenocarcinoma metastases, exposing them to different antibody panels, as each of them has specific antigens. To validate the diagnosis of mesothelioma versus that of adenocarcinoma, two positive mesothelioma markers (anticalretinin, anticytokeratin CK5/6, antiWilms tumour antigen-1, or antiepithelial membrane antigen) and two negative markers for adenocarcinoma (anti-Ber-EP4, monoclonal anticarcinoembryonic antigen, antithyroid transcription factor-1, or anti-MOC-31) are required [29]. These markers can also establish the origin of adenocarcinoma with pleural metastases. Lymphocyte subtype analysis can identify hematological MPE in a specific cohort of patients with an undiagnosed PE [30].

2.3. Pleural Biopsy. Pleural biopsy is the gold standard procedure for the diagnosis of MPE [13]. Percutaneous pleural biopsy has a lower diagnostic sensitivity than cytology, as malignant parietal pleura infiltrates have a patchy pattern (46\%) [31]. Its sensitivity, however, can reach $87-94 \%$ under ultrasound or CT guidance $[32,33]$. In MPE with a pleural thickening $>1 \mathrm{~cm}$ on chest X-ray, the diagnostic sensitivity of CT-guided pleural biopsy is similar to that of thoracoscopy (96\% versus 95\%) [34]. In addition, in an ultrasound-guided biopsy, tru-cut needles have better sensitivity than Abrams (70 versus 44\%) [35]. When pleural thickening is millimetric or has difficult access, pleural biopsy can be performed by thoracoscopy (medical, under local anesthesia, or surgical under general anesthesia). The two procedures are useful to simultaneously visualize the pleura, perform a biopsy of the involved areas, and perform a PF drainage; in addition, if the pleura is infiltrated and in the absence of a trapped lung, pleurodesis can be performed.

Medical thoracoscopy is a safe procedure with low rates of complications and mortality and with a high diagnostic performance. It is very useful in patients not candidates for 
surgery or at increased risk of complications if more invasive procedures are used, such as video-assisted thoracoscopic surgery that requires general anesthesia [36]. The performance of these procedures (medical or surgical thoracoscopy) is similar [24, 37] and mortality and major complication rates are low (between $0-0.34 \%$ and $1.2-1.8 \%$, respectively $[5,38,39])$.

2.4. Pleural Manometry. The indication of pleural manometry is to identify a nonexpandable lung through the calculation of pleural elastance (ability of the lung to return to its natural position after the extraction of PF). Its relevance is that the trapped lung (the lung does not reexpand to its normal position and the pleural elastance is elevated) is related to the failure of pleurodesis, since there is not a sufficient apposition between the pleural leaves. However, in the only randomized study conducted so far, Lentz et al. demonstrated that routine use of manometry during thoracentesis does not reduce chest discomfort related to the procedure and does not prevent against reexpansion pulmonary edema or pneumothorax ex vacuo [40]. Nevertheless, this data must be interpreted carefully. These measurements may not reflect the pressures of the pleural cavity, as they were only taken during brief interruptions in the drains. Determining the real pressures at the end of the expiration, which change several times during the respiratory cycle, is complex and may not be accurate [41].

2.5. Analysis of Pleural Fluid. PE can be a lymphocyte-rich exudate, although they can also be transudative [42]. PF is not associated with relevant biochemical characteristics, and determination of tumour markers has not conclusively proven to be useful. Analysis of PF was reported to have a general sensitivity of $54 \%$ in a study based on the determination of four markers (CEA, CA125, CA15-3, and cytokeratin [19]). In this study, cut-off points were established above the highest values observed in benign PEs. The authors concluded that these markers can be useful to identify the patients who will benefit the most from future invasive procedures for suspicion of MPE [43]. In general, the sensitivity and specificity of these markers are low [44], and they do not spare cytohistological confirmation.

Mesothelin is expressed in normal mesothelial cells and overexpressed in mesothelioma, lung, ovarian, and pancreatic cancer. Although mesothelin has been proposed as a marker for the diagnosis of mesothelioma [45], biomarker testing is recommended only for patients with a suspicious cytology who are not fit to undergo more invasive diagnostic testing [14].

Distinguishing reactive lymphocytes from hematopoietic malignant tumours may be challenging. In this setting, the diagnostic performance of PF flow cytometry is limited, and it should only be used in the presence of atypical cytological findings, a high clinical suspicion, or known history [46]. In PE secondary to multiple myeloma, a cytology or a monoclonal peak in PF have a very high diagnostic performance. Fluid is generally a lymphocytic-rich serohematic exudate with very high protein levels [47].

\section{Management}

The purpose of MPE therapies is to alleviate its symptoms, mainly dyspnea. Whereas asymptomatic effusions only require observation [2], the therapeutic options for symptomatic MPE include repeat therapeutic thoracentesis, thoracic drainage with pleurodesis, the insertion of an IPC, or surgery. The therapeutic choice should be made on a caseby-case basis, considering clinical factors and patient's preferences. Predicting the survival expectancy of a patient with MPE can contribute to a better therapeutic choice. Some tools have been developed and validated to assess the risk of mortality, such as the LENT score, based on lactate dehydrogenase in PF, the Eastern Cooperative Oncology Group performance score, the neutrophil/lymphocyte ratio, and type of tumour (Table 1), which estimates the risk of mortality based on the score obtained [48].

3.1. Therapeutic Thoracentesis. Therapeutic thoracentesis is recommended for all patients with an MPE involving $50 \%$ of the hemithorax and dyspnea. Although MPE can be caused by a variety of clinical problems, its symptoms generally improve after drainage. Subsequently, a definitive palliative intervention can be performed (IPC, pleurodesis, or both) [49]. In the absence of lung reexpansion, the treatment of choice is IPC to spare the patient the discomfort of recurrent unsuccessful pleurodesis. In patients with a life expectancy limited to a few days or weeks, repeated thoracentesis, up to a maximum of $1.5 \mathrm{~L}$, may be performed to try to relieve symptoms (usually dyspnea, cough, or chest pain) $[1,3]$.

3.2. Thoracic Drainage and Pleurodesis. The purpose of pleurodesis is to induce an inflammatory response in the pleura that forces the adhesion of the two layers of the pleura to prevent the accumulation of fluid. The literature demonstrates that pleurodesis improves dyspnea, increases survival [50], and reduces the length of hospital stay and the need for future interventions [11,51-59]. Pleurodesis is not recommended in the presence of a trapped lung $(30 \%$ of cases) $[60,61]$, or multiple pleural septa, since the apposition of the two layers of the pleura will not be achieved and pleurodesis will be unsuccessful. The probability of success will increase if $\mathrm{pH}$ is $<7.20$ or effusion is $>50 \%$ of the hemithorax [62].

There are some aspects to be clarified, as the sclerosing agent to be used, the size of the drain tubes to be inserted, or the administration of nonsteroid anti-inflammatory agents to control pain.

Although the optimal agent for chemical pleurodesis has not yet been identified, talc is the most widely used agent for its availability and cost-effectiveness [49]. Talc can be administered in two forms: through the thoracoscope tube using an aerosol canister (talc poudrage) or via an intercostal tube as a suspension (talc slurry). Antibiotics (tetracycline, doxycycline, and bleomycin), bacterial agents (Corynebacterium parvum, OK432), or silver nitrate and iodopovidone have also been used. A recent meta-analysis of 62 randomized trials involving a total of 3,428 patients 
TABLE 1: A prognostic score for malignant pleural effusions (LENT) [33].

\begin{tabular}{|c|c|c|}
\hline & Variable & Score \\
\hline \multirow{3}{*}{$\mathrm{L}$} & LDH in pleural fluid & \\
\hline & $<1,500 \mathrm{UI} / \mathrm{L}$ & 0 \\
\hline & $>1,500 \mathrm{UI} / \mathrm{L}$ & 1 \\
\hline \multirow{5}{*}{$\mathrm{E}$} & ECOG performance score & \\
\hline & $\begin{array}{lll}1 & 0\end{array}$ & 0 \\
\hline & 1 & 1 \\
\hline & 2 & 2 \\
\hline & $3-4$ & 3 \\
\hline \multirow{3}{*}{$\mathrm{N}$} & Neutrophil/lymphocyte ratio & \\
\hline & $<<$ & 0 \\
\hline & $>9$ & 1 \\
\hline \multirow{8}{*}{$\mathrm{T}$} & Type of tumour & \\
\hline & Low risk (mesothelioma and hematologic malignancies) & 0 \\
\hline & Moderate risk (breast cancer, gynecological, and renal cell carcinoma) & 1 \\
\hline & High risk (lung cancer and other tumours) & 2 \\
\hline & Risk by category & Total score \\
\hline & Low risk (median of survival: 319 days) & $0-1$ \\
\hline & Moderate risk (median of survival: 130 days) & $2-4$ \\
\hline & High risk (median of survival: 44 days) & $5-7$ \\
\hline
\end{tabular}

ECOG, eastern cooperative oncology group; LDH, lactate dehydrogenase.

suggests that talc insufflation is the most effective method of pleurodesis in preventing the accumulation of fluid. However, the clinical and statistical heterogeneity and the high risk of bias in most of the studies included make further research necessary, to confirm that talc poudrage is more effective that talc slurry and doxycycline [4]. Regardless of whether the sclerosing agent is insufflated via a chest tube or the thoracoscope, hospitalization is required. Whereas insufflation through a chest tube can be performed at bedside with analgesia, the second procedure requires general anesthesia or conscious sedation. Randomized clinical trials have failed to demonstrate the superiority of a technique over the other [60,63], and the British Thoracic Society reports that the efficacy of the two procedures is similar [3]. In a recent study, Bhatnagar et al. compared the efficacy of talc administration of talc poudrage by thoracoscopy under local anesthesia versus talc slurry administered through a chest drain. The rate of pleurodesis failure at 90 days in patients who received talc poudrage was $22 \%(36 / 161)$ versus $24 \%$ (38/159) for the patients who were given talc slurry (OR 0.91; 95\% CI: $0.54-1.55 ; p=0.74)$. Although no significant differences were observed between the two groups, the authors acknowledged that their study had limited power to detect small-albeit potentially relevant-differences [64].

Although a study yielded a rate of success of pleurodesis of $91 \%$ [65], these results have not been attained in other studies. A randomized trial comparing talc poudrage versus talc slurry reported success rates of $71 \%$ and $78 \%$, respectively. However, when patients who died within 30 days or failed to achieve lung reexpansion were included, success rates decreased to $53 \%$ and $60 \%$, respectively [60]. In a recent study, the overall rate of success of pleurodesis was $81.4 \%$ ( $84.9 \%$ for nonmesotheliomas and $73 \%$ for mesotheliomas). The latter may be explained by the lack of normal pleural tissue susceptible of an inflammatory response [66]. When talc is instilled, it is recommended to instill large-particle talc $(>15 \mu \mathrm{m})$ to prevent the development of acute respiratory distress syndrome $[67,68]$. Fever and chest pain are other complications of intrapleural talc [12].

The size of the drainage tube is another matter of controversy. Previous studies had documented a similar rate of success for small-bore chest tubes (10-14 F) and large-bore chest tubes when used to insufflate a sclerosing agent [69-71]. However, the TIME-1 trial suggests that large-bore tubes are superior to small-bore tubes in performing pleurodesis [11]. Moreover, small-bore chest tubes are more comfortable for patients [12]. The same study revealed that the administration of nonsteroidal anti-inflammatories to control pain does not affect pleurodesis outcomes [12]. No clinical data have been published on the potential deleterious effects of the administration of corticosteroids on the efficacy of pleurodesis. Therefore, their use should be avoided whenever it is possible. In addition, rotation of the patient has not been demonstrated to improve the rate of successful pleurodesis [72].

3.3. Indwelling Pleural Catheter. IPC are silicone tubes that are inserted percutaneously. They have a one-way valve and maintain lung expansion by intermittently draining pleural fluid instead of inducing pleural space obliteration, as in the case of pleurodesis. The purpose of IPC is to control symptoms without hospitalization (Figure 1). IPCs are as effective as pleurodesis as a first-line treatment of MPE $[11,59]$ and can be used in the presence of a trapped lung. A systematic review of 19 studies involving 1,370 patients assessing the efficacy and safety of IPC for MPE revealed an improvement of symptoms in $95 \%$ of cases [73]. IPC can achieve spontaneous pleurodesis in $46-70 \%$ of patients with full lung expansion caused by local inflammation induced by the tumour or the IPC $[73,74]$. 


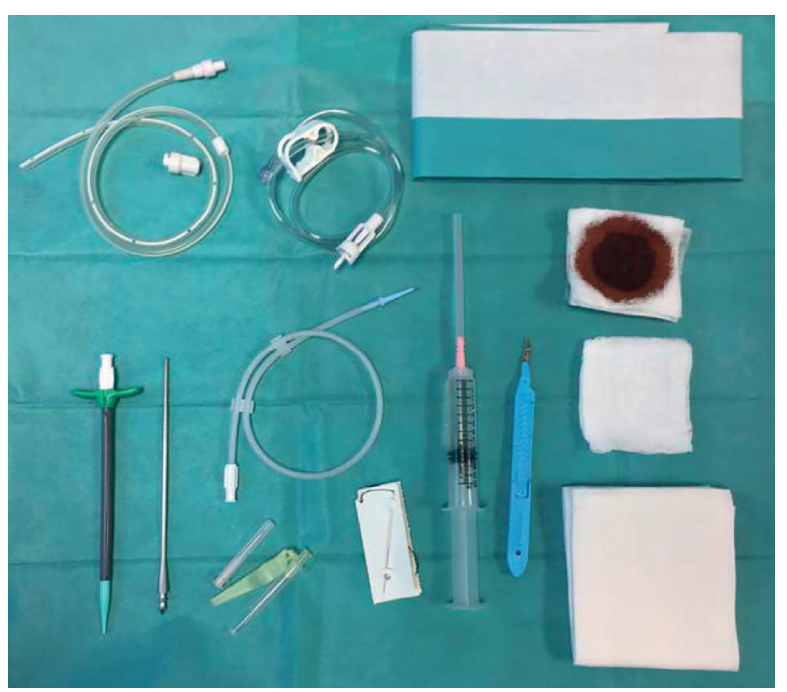

(a)

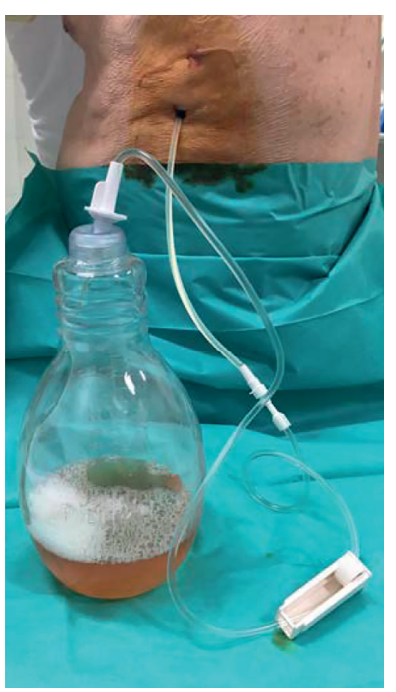

(b)

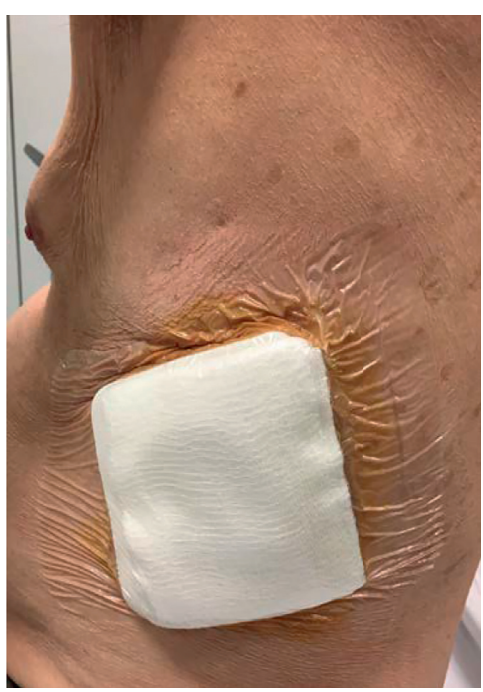

(c)

Figure 1: (a) Example of indwelling pleural catheter set. (b) Drainage of indwelling pleural catheter with vacuum bottle. (c) IPC with dressing.

To date, no supporting evidence has been provided on the superiority of a technique over another (IPC versus talc pleurodesis). IPC requires a shorter hospital stay and less repetition of pleural procedures [75] and is more effective in the presence of a trapped lung or in patients with a poor functional status that cannot tolerate pleurodesis. In five studies involving 133 patients with MPE and a trapped lung, symptoms improved by more than $94 \%$ in patients with an IPC [76-80]. The AMPLE study compared the length of hospital stay from the procedure (IPC versus talc pleurodesis) until death or at 12 months in 146 patients with MPE. In the first group, the median hospital stay was 10 days (interquartile range 3-17) versus $12(7-21)$ in the second group $(p=0.03)$. Although the clinical relevance of this difference is uncertain, these findings may guide the therapeutic decision [54]. PE can be more rapidly solved by pleurodesis, but it is more invasive and will probably require recurrent aspiration $[11,59]$. IPC is more suitable for ambulatory patients, although drainage by IPC is more time-consuming and requires more intensive care in patients who have undergone unsuccessful pleurodesis. The two procedures are effective in achieving the relief of symptoms and improving quality of life, without significant differences between the two. The AMPLE-2 trial, which involved 87 patients with an MPE treated with an IPC, compared the optimal drainage protocol (daily or only in the presence of symptoms). No differences were found between the two techniques in terms of dyspnea control, but a higher rate of success of pleurodesis at 2 and 6 months was achieved with the more invasive drain method [81]. The results of this study are consistent with the ones of the ASAP trial [82]. Figure 2 contains a summary of the trials on this issue that have been published or are in recruitment phase.

IPC are associated with higher complication rates (drain blockade or malposition $(<5 \%)$ [83], catheter rupture [84], and subcutaneous and pleural infections (0-12\%)) [85-87], although they are generally well tolerated without a significant morbidity [59]. Another potential complication related to the use of IPC is tumour seeding of the catheter tract, which occurs in $5 \%$ of cases based on the type of tumour and time of use of the IPC [86]. Prophylactic use of radiotherapy has not been documented to exert any beneficial effect and routine use in clinical practice is not recommended [88].

Little evidence has been published of the cost of the management of IPC/talc pleurodesis, as most studies are retrospective and perform an indirect comparison with conventional treatments. The TIME- 2 study, carried out prospectively, did not reveal any differences between these techniques in terms of cost [89]. A cost-effectiveness analysis performed alongside the TIME2 trial suggested that IPC is cost-effective compared to talc: to a greater extent in patients with limited survival and less so if significant nursing resources are required to assist with weekly drainage [90].

IPC can be more cost-effective in patients with a limited life expectancy ( $<3$ months), whereas talc pleurodesis is more cost-effective in patients with a higher life expectancy [91].

3.4. Associated Procedures. The combination of several treatments, especially IPC chemical pleurodesis, is a plausible alternative in an attempt to reduce the length of hospitalization and time of catheter use. In a recent study, 154 patients with MPE were implanted an IPC, and PF was evacuated in ambulatory care. Patients with a trapped lung were randomized to receive either talc or placebo via the IPC. The results showed that pleurodesis was achieved in $43 \%(30 / 69)$ of patients who were administered talc, and in $23 \%(16 / 70)$ of subjects in the placebo group (HR 2.20; $95 \%$ CI: $1.23-3.92 ; p=0.008$ ), without any adverse effects [92]. 


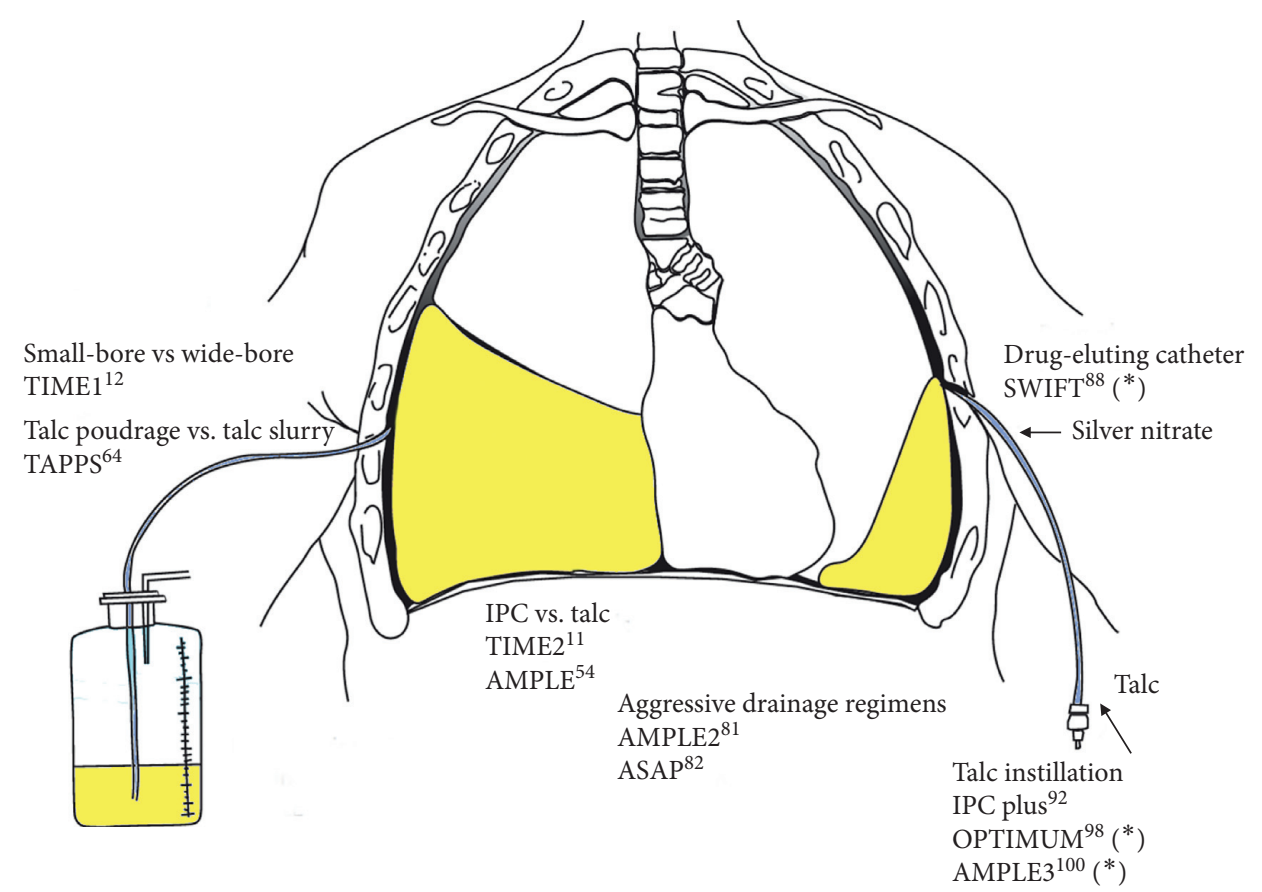

FIgURE 2: Recent trials addressing the management of malignant pleural effusion (modified under authorization) [41]. IPC, indwelling pleural catheter. ${ }^{*}$ In recruitment phase.

TABLE 2: Main trials investigating management of malignant pleural effusion.

\begin{tabular}{|c|c|c|c|}
\hline Authors and references & $\begin{array}{c}\text { Year of } \\
\text { publication }\end{array}$ & Comparator & Commentary \\
\hline Davies et al. [11] (TIME2) & 2012 & IPC versus talc pleurodesis & $\begin{array}{c}\text { No significant differences between the two groups } \\
\text { to relieve dyspnea }\end{array}$ \\
\hline Rahman et al. [12] (TIME1) & 2015 & $\begin{array}{l}\text { Use of nonsteroidal anti- } \\
\text { inflammatory drugs (NSAID) } \\
\text { and chest drain size }\end{array}$ & $\begin{array}{l}\text { NSAID versus opiates was associated with more } \\
\text { need for rescue medication in the first with no } \\
\text { lower rates of pleurodesis efficacy. The } 12 \mathrm{~F} \text { versus } \\
24 \mathrm{~F} \text { chest tubes were associated with pain } \\
\text { reduction but did not meet the noninferiority } \\
\text { criteria for the efficacy of pleurodesis. }\end{array}$ \\
\hline Thomas et al. [54] (AMPLE) & 2017 & IPC versus talc pleurodesis & $\begin{array}{c}\text { Median hospitalization days was lower in IPC } \\
\text { patients }(p=0.03)\end{array}$ \\
\hline Wahidi et al. [82] (ASAP) & 2017 & $\begin{array}{l}\text { IPC: Daily drainage versus } \\
\text { symptom-guided drainage }\end{array}$ & $\begin{array}{l}\text { Higher success rate of pleurodesis with aggressive } \\
\text { drainage, without improving control of dyspnea }\end{array}$ \\
\hline Muruganandan et al. [81] (AMPLE2) & 2018 & $\begin{array}{l}\text { IPC: Daily drainage versus } \\
\text { symptom-guided drainage }\end{array}$ & $\begin{array}{l}\text { Higher success rate of pleurodesis with aggressive } \\
\text { drainage, without improving control of dyspnea }\end{array}$ \\
\hline Bhatnagar et al. [92] (IPC plus) & 2018 & $\begin{array}{l}\text { Talc pleurodesis through IPC } \\
\text { versus placebo }\end{array}$ & $\begin{array}{l}\text { Pleurodesis in } 43 \% \text { and } 23 \% \text {, respectively } \\
\qquad(p=0.008)\end{array}$ \\
\hline Mishra et al. [96] (TIME3) & 2018 & $\begin{array}{l}\text { Intrapleural urokinase versus } \\
\text { placebo }\end{array}$ & $\begin{array}{c}\text { Urokinase does not reduce dyspnea or improve } \\
\text { pleurodesis success rate }\end{array}$ \\
\hline Bhatnagar et al. [64] (TAPPS) & 2019 & $\begin{array}{c}\text { Talc poudrage by thoracoscopy } \\
\text { versus talc slurry by chest } \\
\text { drainage }\end{array}$ & $\begin{array}{l}\text { Pleurodesis failure rate of } 22 \% \text { in the first group } \\
\text { and } 24 \% \text { in the second }(p=0.74)\end{array}$ \\
\hline Sivakumar et al. [98] (OPTIMUM) & - $^{*}$ & $\begin{array}{l}\text { Talc pleurodesis through IPC } \\
\text { versus chest drainage (small } \\
\text { size) }\end{array}$ & Improving the quality of life will be assessed \\
\hline $\begin{array}{l}\text { ClinicalTrials.gov identifier: } \\
\text { NCT02649894 [99] (SWIFT) } \\
\text { Anzctr.org.au identifier: }\end{array}$ & - $^{*}$ & $\begin{array}{l}\text { Silver nitrate eluting catheter } \\
\text { versus standard IPC }\end{array}$ & The success rate of pleurodesis will be assessed \\
\hline $\begin{array}{l}\text { ACTRN12618001013257 [100] } \\
\text { (AMPLE3) }\end{array}$ & $-^{*}$ & IPC versus VATS pleurodesis & Requirement for ipsilateral pleural procedure \\
\hline Matthews et al. [101] (MESOTRAP) & $一^{*}$ & VATS-PD versus standard IPC & $\begin{array}{c}\text { Improvement of dyspnea will be assess in patients } \\
\text { with trapped lung and malignant pleural } \\
\text { mesothelioma }\end{array}$ \\
\hline
\end{tabular}

*Unpublished results; VATS, video-assisted thoracoscopy surgery; VATS-PD, video-assisted thoracoscopic partial pleurectomy or decortication. 


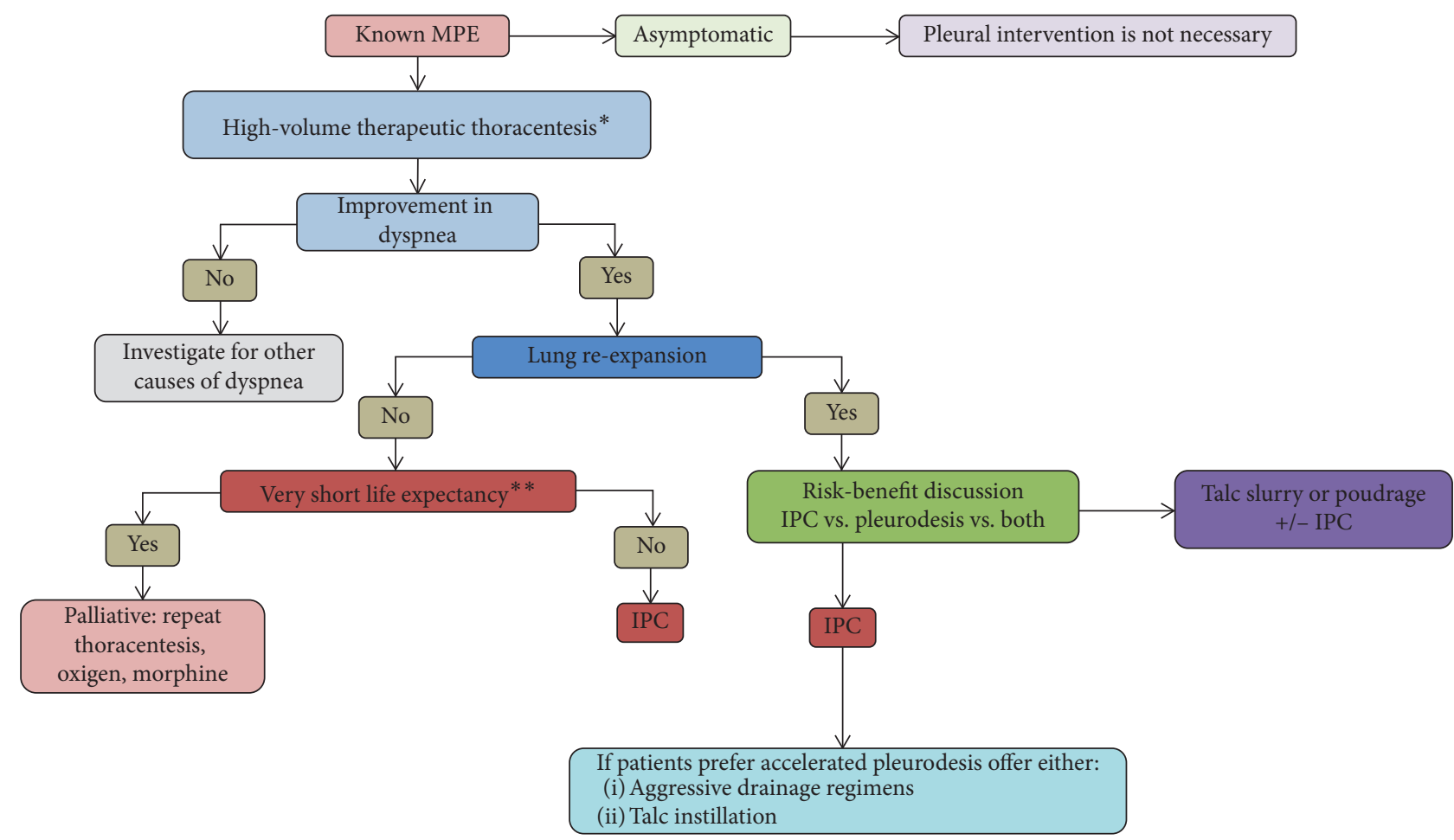

FIGURe 3: Management of patients with known malignant pleural effusion (adapted from Feller-Kopman et al.) [1]. IPC, indwelling pleural catheter; MPE, malignant pleural effusion. ${ }^{*}$ With the aim of evaluating lung expansion and improvement of dyspnea. ${ }^{* *}$ In an approximate and individualized fashion.

3.5. Other Intrapleural Treatments. Two randomized phase II studies investigated the use of a monoclonal antibody, bevacizumab, intrapleurally. In the first, performed in patients with non-small cell lung cancer and MPE, the treatment arm with this drug obtained a greater reduction in the size of PE and symptoms, with a higher survival rate per year of follow-up. Adverse events were similar among the groups [93]. In the second, performed in patients with nonsquamous non-small cell lung cancer and MPE, better MPE response rates were observed with the addition of bevacizumab [94]. Also, in malignant pleural mesotheliomas, the role of gene therapy and immunotherapy can change the management of these patients [95]. However, more clinical trials are needed to determine the efficacy of these treatments.

In a recent clinical trial, 71 patients with an MPE who did not drain were randomized to receive urokinase or placebo. No differences were found between the groups in terms of dyspnea and the failure of pleurodesis $(37 \%$ and $32 \%$, respectively). In contrast, the group receiving urokinase observed a greater decrease in PE size $(-19 \%$ versus $-11 \%$; $p<0.001$ ), a lower hospital stay (1.6 daysversus 2.6; p.049) and improved survival (69 days versus $48 ; p=0.026$ ). Their conclusions are that use of intrapleural urokinase does not reduce dyspnea or improve pleurodesis success compared with placebo and cannot be recommended as an adjunct to pleurodesis [96].

3.6. Surgery. Surgical pleurectomy has a limited role in the management of MPE, and the supposed benefits may not outweigh the perioperative mortality and worsening of quality of life [3]. A study on mesothelioma-related MPE revealed that talc pleurodesis may be preferable to surgery, as it is associated with lower rates of complications and a shorter length of hospitalization [97].

3.7. Future Clinical Trials. Three trials on this issue are ongoing at this moment, the OPTIMUM trial (comparing the improvement in quality of life achieved by IPC talc pleurodesis versus chest-tube talc pleurodesis) [98]; the SWIFT trial (comparing the rates of successful pleurodesis via silver nitratecoated IPC versus standard IPC) [99]; and the AMPLE3 trial [100] (comparing the advantages of IPC and talc pleurodesis versus video-assisted thoracoscopy); and MESOTRAP [101] (randomised controlled clinical trial comparing video-assisted thoracoscopic partial pleurectomy or decortication with IPC in patients with trapped lung and malignant pleural mesothelioma). Table 2 shows a summary of the main trials that evaluate the management of MPE with the results obtained.

\section{Conclusions}

The optimal management of patients with MPE is still unclear. This problem requires a multidisciplinary approach. Less-invasive diagnostic tests are the initial step. If results are negative, more invasive techniques are required taking into account patient's preferences, their functional status and life expectancy, the type of tumour, experience of the medical team, or the presence of a trapped lung. At present, the management of pleural effusion has evolved towards less invasive approaches based on ambulatory care. This 
approach spares the patient the discomfort caused by more invasive interventions and reduces its economic burden.

The evidence currently available on the management of symptomatic MPE suggests that both, talc pleurodesis (poudrage or slurry) and IPC, are effective in reducing fluid accumulation and in the relief of symptoms (Figure 3). Limited data has been provided demonstrating the superiority of one over another (poudrage versus slurry). Although IPC reduces the length of hospitalization, long-term use is associated with a higher risk for adverse events. In the presence of a trapped lung, IPC is more effective in improving symptoms. In the case of loculated MPE, the use of intrapleural fibrinolytics is not supported by evidence, and oncologic treatments are not currently recommended as an alternative option to mechanical drainage. Further research is needed to shed light on the current matters of controversy such as performing pleurodesis with less invasive techniques or being able to offer each patient a personalized approach to managing their MPE, based on variables (e.g., symptoms, type of cancer, or size of $\mathrm{PE}$ ) that could predict the individual response and prognosis of each patient.

\section{Abbreviations}

CT : Computed tomography

IPC : Indwelling pleural catheter

MPE : Malignant pleural effusion

MR : Magnetic resonance

PE : Pleural effusion

PET : Positron emission tomography

PF : Pleural fluid.

\section{Conflicts of Interest}

The authors declare no conflicts of interest.

\section{Authors' Contributions}

All authors contributed equally to the authorship, drafting, conception, and design of the manuscript and approved the final version.

\section{References}

[1] D. J. Feller-Kopman, C. B. Reddy, M. M. DeCamp et al., "Management of malignant pleural effusions. An official ATS/STS/STR clinical practice guideline," American Journal of Respiratory and Critical Care Medicine, vol. 198, no. 7, pp. 839-849, 2018.

[2] J. M. Porcel, A. Gasol, S. Bielsa, C. Civit, R. W. Light, and A. Salud, "Clinical features and survival of lung cancer patients with pleural effusions," Respirology, vol. 20, no. 4, pp. 654-659, 2015.

[3] M. E. Roberts, E. Neville, R. G. Berrisford, G. Antunes, and N. J. Ali, "Management of a malignant pleural effusion: British Thoracic Society pleural disease guideline 2010," Thorax, vol. 65, no. Suppl 2, pp. ii32-ii40, 2010.

[4] A. O. Clive, H. E. Jones, R. Bhatnagar, N. J. Preston, and N. Maskell, "Interventions for the management of malignant pleural effusions: a network meta-analysis," The Cochrane database of systematic reviews, vol. 5, Article ID CD010529, 2016.

[5] N. M. Rahman, N. J. Ali, G. Brown et al., "Local anaesthetic thoracoscopy: British thoracic society pleural disease guideline 2010," Thorax, vol. 65, no. Suppl 2, pp. ii54-ii60, 2010.

[6] American Thoracic Society, "Management of malignant pleural effusions," American Journal of Respiratory and Critical Care Medicine, vol. 162, no. 5, pp. 1987-2001, 2000.

[7] N. Taghizadeh, M. Fortin, and A. Tremblay, "US hospitalizations for malignant pleural effusions," Chest, vol. 151, no. 4, pp. 845-854, 2017.

[8] D. E. Ost, J. Niu, H. Zhao, H. B. Grosu, and S. H. Giordano, "Quality gaps and comparative effectiveness of management strategies for recurrent malignant pleural effusions," Chest, vol. 153, no. 2, pp. 438-452, 2018.

[9] R. Thomas, R. Francis, H. E. Davies, and Y. C. G. Lee, "Interventional therapies for malignant pleural effusions: the present and the future," Respirology, vol. 19, no. 6, pp. 809-822, 2014.

[10] M. M. S. Lui, D. B. Fitzgerald, and Y. C. G. Lee, "Phenotyping malignant pleural effusions," Current Opinion in Pulmonary Medicine, vol. 22, no. 4, pp. 350-355, 2016.

[11] H. E. Davies, E. K. Mishra, B. C. Kahan et al., "Effect of an indwelling pleural catheter vs chest tube and talc pleurodesis for relieving dyspnea in patients with malignant pleural effusion," Journal of the American Medical Association, vol. 307, no. 22, pp. 2383-2389, 2012.

[12] N. M. Rahman, J. Pepperell, S. Rehal et al., "Effect of opioids vs NSAIDs and larger vs smaller chest tube size on pain control and pleurodesis efficacy among patients with malignant pleural effusion," Journal of the American Medical Association, vol. 314, no. 24, pp. 2641-2653, 2015.

[13] A. C. Bibby, P. Dorn, I. Psallidas et al., "ERS/EACTS statement on the management of malignant pleural effusions," European Respiratory Journal, vol. 52, no. 1, Article ID 1800349, 2018.

[14] I. Woolhouse, L. Bishop, L. Darlison et al., "British Thoracic Society Guideline for the investigation and management of malignant pleural mesothelioma," Thorax, vol. 73, no. Suppl 1, pp. i1-i30, 2018.

[15] J. E. Heffner and J. S. Klein, "Recent advances in the diagnosis and management of malignant pleural effusions," Mayo Clinic Proceedings, vol. 83, no. 2, pp. 235-250, 2008.

[16] C. J. Mercaldi and S. F. Lanes, "Ultrasound guidance decreases complications and improves the cost of care among patients undergoing thoracentesis and paracentesis," Chest, vol. 143, no. 2, pp. 532-538, 2013.

[17] J. M. Porcel and R. W. Light, "Pleural effusions," Disease- $a-$ Month, vol. 59, no. 2, pp. 29-57, 2013.

[18] A. N. Leung, N. L. Müller, and R. R. Miller, "CT in differential diagnosis of diffuse pleural disease," American Journal of Roentgenology, vol. 154, no. 3, pp. 487-492, 1990.

[19] R. J. Hallifax, M. Haris, J. P. Corcoran et al., "Role of CT in assessing pleural malignancy prior to thoracoscopy: table 1," Thorax, vol. 70, no. 2, pp. 192-193, 2015.

[20] J. M. Porcel, P. Hernández, M. Martínez-Alonso, S. Bielsa, and A. Salud, "Accuracy of fluorodeoxyglucose-PET imaging for differentiating benign from malignant pleural effusions," Chest, vol. 147, no. 2, pp. 502-512, 2015.

[21] D. T. Arnold and N. Maskell, "Imaging for malignant pleural effusions-still no routine role of positron emission tomography," Journal of Thoracic Disease, vol. 11, no. 4, pp. 1079-1081, 2019. 
[22] D. De Fonseka, W. Underwood, L. Stadon et al., "Randomised controlled trial to compare the diagnostic yield of positron emission tomography CT (PET-CT) TARGETed pleural biopsy versus CT-guided pleural biopsy in suspected pleural malignancy (TARGET trial)," BMJ Open Respiratory Research, vol. 5, no. 1, Article ID e000270, 2018.

[23] S. Walker, A. C. Bibby, and N. A. Maskell, "Current best practice in the evaluation and management of malignant pleural effusions," Therapeutic Advances in Respiratory Disease, vol. 11, no. 2, pp. 105-114, 2017.

[24] C. Hooper, Y. C. G. Lee, N. Maskell, and BTS Pleural Guideline Group, "Investigation of a unilateral pleural effusion in adults: british thoracic society pleural disease guideline 2010," Thorax, vol. 65, no. Suppl 2, pp. ii4-ii17, 2010.

[25] D. T. Arnold, D. De Fonseka, S. Perry et al., "Investigating unilateral pleural effusions: the role of cytology," European Respiratory Journal, vol. 52, no. 5, Article ID 1801254, 2018.

[26] H. B. Grosu, F. Kazzaz, E. Vakil, S. Molina, and D. Ost, "Sensitivity of initial thoracentesis for malignant pleural effusion stratified by tumor type in patients with strong evidence of metastatic disease," Respiration, vol. 96, no. 4, pp. 363-369, 2018.

[27] W. Abouzgheib, T. Bartter, H. Dagher, M. Pratter, and W. Klump, "A prospective study of the volume of pleural fluid required for accurate diagnosis of malignant pleural effusion," Chest, vol. 135, no. 4, pp. 999-1001, 2009.

[28] J. Swiderek, S. Morcos, V. Donthireddy et al., "Prospective study to determine the volume of pleural fluid required to diagnose malignancy," Chest, vol. 137, no. 1, pp. 68-73, 2010.

[29] A. Scherpereel, P. Astoul, P. Baas et al., "Guidelines of the European respiratory society and the European society of thoracic surgeons for the management of malignant pleural mesothelioma," European Respiratory Journal, vol. 35, no. 3, pp. 479-495, 2010.

[30] G. Dixon, R. Bhatnagar, N. Zahan-Evans et al., "A prospective study to evaluate a diagnostic algorithm for the use of fluid lymphocyte subset analysis in undiagnosed unilateral pleural effusions," Respiration, vol. 95, no. 2, pp. 98-105, 2018.

[31] S. A. Sahn, "The pleura," American Review of Respiratory Disease, vol. 138, no. 1, pp. 184-234, 1988.

[32] N. Maskell, F. Gleeson, and R. Davies, "Standard pleural biopsy versus CT-guided cutting-needle biopsy for diagnosis of malignant disease in pleural effusions: a randomised controlled trial," The Lancet, vol. 361, no. 9366, pp. 1326-1330, 2003.

[33] R. J. Hallifax, J. P. Corcoran, A. Ahmed et al., "Physicianbased ultrasound-guided biopsy for diagnosing pleural disease," Chest, vol. 146, no. 4, pp. 1001-1006, 2014.

[34] M. Metintas, G. Ak, E. Dundar et al., "Medical thoracoscopy vs. CT scan-guided Abrams pleural needle biopsy for diagnosis of patients with pleural effusions," Chest, vol. 137, no. 6, pp. 1362-1368, 2010.

[35] D.-B. Chang, P.-C. Yang, K.-T. Luh, S.-H. Kuo, and C.-J. Yu, "Ultrasound-guided pleural biopsy with Tru-Cut needle," Chest, vol. 100, no. 5, pp. 1328-1333, 1991.

[36] A. H. Alraiyes, S. S. Dhillon, K. Harris et al., "Medical thoracoscopy: technique and application," Pleura, vol. 3, pp. 1-11, 2016.

[37] K. H. Yap, M. J. Phillips, and Y. C. G. Lee, "Medical thoracoscopy," Current Opinion in Pulmonary Medicine, vol. 20, no. 4, pp. 358-365, 2014.
[38] A. Medford, Y. Awan, A. Marchbank, J. Rahamim, J. Unsworth-White, and P. Pearson, "Diagnostic and therapeutic performance of video-assisted thoracoscopic surgery (VATS) in investigation and management of pleural exudates," The Annals of The Royal College of Surgeons of England, vol. 90, no. 7, pp. 597-600, 2008.

[39] R. Agarwal, A. N. Aggarwal, and D. Gupta, "Diagnostic accuracy and safety of semirigid thoracoscopy in exudative pleural effusions," Chest, vol. 144, no. 6, pp. 1857-1867, 2013.

[40] R. J. Lentz, A. D. Lerner, J. K. Pannu et al., "Routine monitoring with pleural manometry during therapeutic large-volume thoracentesis to prevent pleural-pressure-related complications: a multicentre, single-blind randomised controlled trial," The Lancet Respiratory Medicine, vol. 7, no. 5, pp. 447-455, 2019.

[41] S. Walker, R. Mercer, N. A. Maskell, and N. M. Rahman, "Malignant pleural effusion management: keeping the flood gates shut," The Lancet Respiratory Medicine, vol. 8, no. 6, 2019.

[42] L. Ferreiro, F. Gude, M. E. Toubes et al., "Predictive models of malignant transudative pleural effusions," Journal of Thoracic Disease, vol. 9, no. 1, pp. 106-116, 2017.

[43] J. M. Porcel, M. Vives, A. Esquerda, A. Salud, B. Pérez, and F. Rodríguez-Panadero, "Use of a panel of tumor markers (carcinoembryonic antigen, cancer antigen 125, carbohydrate antigen 15-3, and cytokeratin 19 fragments) in pleural fluid for the differential diagnosis of benign and malignant effusions," Chest, vol. 126, no. 6, pp. 1757-1763, 2004.

[44] I. Psallidas, I. Kalomenidis, J. M. Porcel, B. W. Robinson, and G. T. Stathopoulos, "Malignant pleural effusion: from bench to bedside," European Respiratory Review, vol. 25, no. 140, pp. 189-198, 2016.

[45] H. E. Davies, R. S. Sadler, S. Bielsa et al., "Clinical impact and reliability of pleural fluid mesothelin in undiagnosed pleural effusions," American Journal of Respiratory and Critical Care Medicine, vol. 180, no. 5, pp. 437-444, 2009.

[46] M. Y. Fuller and M. J. Thrall, "Utility of flow cytometry analysis for pleural and peritoneal fluids," Journal of the American Society of Cytopathology, vol. 5, no. 6, pp. 339-344, 2016.

[47] V. Riveiro, L. Ferreiro, M. E. Toubes, A. Lama, J. M. ÁlvarezDobaño, and L. Valdés, "Características de los pacientes con derrame pleural mielomatoso. Revisión sistemática," Revista Clínica Española, vol. 218, no. 2, pp. 89-97, 2018.

[48] A. O. Clive, B. C. Kahan, C. E. Hooper et al., "Predicting survival in malignant pleural effusion: development and validation of the LENT prognostic score," Thorax, vol. 69, no. 12, pp. 1098-1104, 2014.

[49] Y. C. G. Lee, M. H. Baumann, N. A. Maskell et al., "Pleurodesis practice for malignant pleural effusions in five English-speaking countries," Chest, vol. 124, no. 6, pp. 2229-2238, 2003.

[50] M. Hassan, R. M. Mercer, N. A. Maskell et al., "Survival in patients with malignant pleural effusion undergoing talc pleurodesis," Lung Cancer, vol. 137, pp. 14-18, 2019.

[51] J. B. Putnam Jr., R. W. Light, R. M. Rodriguez et al., "A randomized comparison of indwelling pleural catheter and doxycycline pleurodesis in the management of malignant pleural effusions," Cancer, vol. 86, no. 10, pp. 1992-1999, 1999.

[52] R. C. Boshuizen, V. Vd Noort, J. A. Burgers et al., "A randomized controlled trial comparing indwelling pleural catheters with talc pleurodesis (NVALT-14)," Lung Cancer, vol. 108, pp. 9-14, 2017. 
[53] T. L. Demmy, L. Gu, J. E. Burkhalter et al., "Optimal management of malignant pleural effusions (results of CALGB 30102)," Journal of the National Comprehensive Cancer Network, vol. 10, no. 8, pp. 975-982, 2012.

[54] R. Thomas, E. T. H. Fysh, N. A. Smith et al., "Effect of an indwelling pleural catheter vs talc pleurodesis on hospitalization days in patients with malignant pleural effusion," Journal of the American Medical Association, vol. 318, no. 19, pp. 1903-1912, 2017.

[55] R. K. Freeman, A. J. Ascioti, and R. S. Mahidhara, "A propensity-matched comparison of pleurodesis or tunneled pleural catheter in patients undergoing diagnostic thoracoscopy for malignancy," The Annals of Thoracic Surgery, vol. 96, no. 1, pp. 259-264, 2013.

[56] B. M. Hunt, A. S. Farivar, E. Vallières et al., "Thoracoscopic talc versus tunneled pleural catheters for palliation of malignant pleural effusions," The Annals of Thoracic Surgery, vol. 94, no. 4, pp. 1053-1059, 2012.

[57] J. B. Putnam Jr., G. L. Walsh, S. G. Swisher et al., "Outpatient management of malignant pleural effusion by a chronic indwelling pleural catheter," The Annals of Thoracic Surgery, vol. 69, no. 2, pp. 369-375, 2000.

[58] N. Srour, K. Amjadi, A. J. Forster, and S. D. Aaron, "Management of malignant pleural effusions with indwelling pleural catheters or talc pleurodesis," Canadian Respiratory Journal, vol. 20, no. 2, pp. 106-110, 2013.

[59] E. T. H. Fysh, G. W. Waterer, P. A. Kendall et al., "Indwelling pleural catheters reduce inpatient days over pleurodesis for malignant pleural effusion," Chest, vol. 142, no. 2, pp. 394-400, 2012.

[60] C. M. Dresler, J. Olak, J. E. Herndon et al., "Phase III intergroup study of talc poudrage vs talc slurry sclerosis for malignant pleural effusion," Chest, vol. 127, no. 3, pp. 909-915, 2005.

[61] A. C. Bibby, P. Halford, D. De Fonseka, A. J. Morley, S. Smith, and N. A. Maskell, "The prevalence and clinical relevance of nonexpandable lung in malignant pleural mesothelioma. A prospective, single-center cohort study of 229 patients," Annals of the American Thoracic Society, vol. 16, no. 10, pp. 1273-1279, 2019.

[62] E. T. H. Fysh, S. Bielsa, C. A. Budgeon et al., "Predictors of clinical use of pleurodesis and/or indwelling pleural catheter therapy for malignant pleural effusion," Chest, vol. 147, no. 6, pp. 1629-1634, 2015.

[63] A. P. C. Yim, A. T. C. Chan, W. L. Tak, I. Y. P. Wan, and J. K. S. Ho, "Thoracoscopic talc insufflation versus talc slurry for symptomatic malignant pleural effusion," The Annals of Thoracic Surgery, vol. 62, no. 6, pp. 1655-1658, 1996.

[64] R. Bhatnagar, H. E. G. Piotrowska, M. Laskawiec-Szkonter et al., "Effect of thoracoscopic talc poudrage vs. talc slurry via chest tube on pleurodesis failure rate among patients with malignant pleural effusions: a randomized clinical trial," Journal of the American Medical Association, vol. 23, no. 1, pp. 63-69, 2020.

[65] L. Kennedy and S. A. Sahn, "Talc pleurodesis for the treatment of pneumothorax and pleural effusion," Chest, vol. 106, no. 4, pp. 1215-1222, 1994.

[66] R. M. Mercer, J. Macready, H. Jeffries et al., "Clinically important associations of pleurodesis success in malignant pleural effusion: analysis of the TIME1 data set," Respirology, vol. 25, no. 7, pp. 750-755, 2019.

[67] N. A. Maskell, Y. C. G. Lee, F. V. Gleeson, E. L. Hedley, G. Pengelly, and R. J. O. Davies, "Randomized trials describing lung inflammation after pleurodesis with talc of varying particle size," American Journal of Respiratory and Critical Care Medicine, vol. 170, no. 4, pp. 377-382, 2004.

[68] J. P. Janssen, G. Collier, P. Astoul et al., "Safety of pleurodesis with talc poudrage in malignant pleural effusion: a prospective cohort study," The Lancet, vol. 369, no. 9572, pp. 1535-1539, 2007.

[69] K. G. Seaton, E. F. Patz Jr., and P. C. Goodman, "Palliative treatment of malignant pleural effusions: value of small-bore catheter thoracostomy and doxycycline sclerotherapy," American Journal of Roentgenology, vol. 164, no. 3, pp. 589-591, 1995.

[70] M. C. Morrison, P. R. Mueller, M. J. Lee et al., "Sclerotherapy of malignant pleural effusion through sonographically placed small-bore catheters," American Journal of Roentgenology, vol. 158, no. 1, pp. 41-43, 1992.

[71] L. A. Parker, G. C. Charnock, and D. J. Delany, "Small bore catheter drainage and sclerotherapy for malignant pleural effusions," Cancer, vol. 64, no. 6, pp. 1218-1221, 1989.

[72] H.-J. Mager, B. Maesen, F. Verzijlbergen, and F. Schramel, "Distribution of talc suspension during treatment of malignant pleural effusion with talc pleurodesis," Lung Cancer, vol. 36, no. 1, pp. 77-81, 2002.

[73] A. Tremblay, C. Mason, and G. Michaud, "Use of tunnelled catheters for malignant pleural effusions in patients fit for pleurodesis," European Respiratory Journal, vol. 30, no. 4, pp. 759-762, 2007.

[74] M. E. M. Van Meter, K. Y. McKee, and R. J. Kohlwes, "Efficacy and safety of tunneled pleural catheters in adults with malignant pleural effusions: a systematic review," Journal of General Internal Medicine, vol. 26, no. 1, pp. 7076, 2011.

[75] N. P. Iyer, C. B. Reddy, M. M. Wahidi et al., "Indwelling pleural catheter versus pleurodesis for malignant pleural effusions. A systematic review and meta-analysis," Annals of the American Thoracic Society, vol. 16, no. 1, pp. 124-131, 2019.

[76] W. H. Warren, R. Kalimi, L. M. Khodadadian, and A. W. Kim, "Management of malignant pleural effusions using the PleurX catheter," The Annals of Thoracic Surgery, vol. 85, no. 3, pp. 1049-1055, 2008.

[77] G. W. Pien, M. J. Gant, C. L. Washam, and D. H. Sterman, "Use of an implantable pleural catheter for trapped lung syndrome in patients with malignant pleural effusion," Chest, vol. 119, no. 6, pp. 1641-1646, 2001.

[78] R. A. Qureshi, S. L. Collinson, R. J. Powell, P. O. Froeschle, and R. G. Berrisford, "Management of malignant pleural effusion associated with trapped lung syndrome," Asian Cardiovascular and Thoracic Annals, vol. 16, no. 2, pp. 120-123, 2008.

[79] L. M. Van den Toorn, E. Schaap, V. F. M. Surmont, E. M. Pouw, K. C. D. Van der Rijt, and R. J. Van Klaveren, "Management of recurrent malignant pleural effusions with a chronic indwelling pleural catheter," Lung Cancer, vol. 50, no. 1, pp. 123-127, 2005.

[80] J. A. Burgers, A. Olijve, and P. Baas, "Chronic indwelling pleural catheter for malignant pleural effusion in 25 patients," Nederlands Tijdschrift Voor Geneeskunde, vol. 150, pp. 1618-1623, 2006.

[81] S. Muruganandan, M. Azzopardi, D. B. Fitzgerald et al., "Aggressive versus symptom-guided drainage of malignant pleural effusion via indwelling pleural catheters (AMPLE-2): an open-label randomised trial," The Lancet Respiratory Medicine, vol. 6, no. 9, pp. 671-680, 2018. 
[82] M. M. Wahidi, C. Reddy, L. Yarmus et al., "Randomized trial of pleural fluid drainage frequency in patients with malignant pleural effusions. The ASAP Trial," American Journal of Respiratory and Critical Care Medicine, vol. 195, no. 8, pp. 1050-1057, 2017.

[83] J. M. Wrightson, E. Fysh, N. A. Maskell, and Y. C. Lee, "Risk reduction in pleural procedures: sonography, simulation and supervision," Current Opinion in Pulmonary Medicine, vol. 16, no. 4, pp. 340-350, 2010.

[84] E. T. H. Fysh, J. M. Wrightson, Y. C. G. Lee, and N. M. Rahman, "Fractured indwelling pleural catheters," Chest, vol. 141, no. 4, pp. 1090-1094, 2012.

[85] E. T. H. Fysh, A. Tremblay, D. Feller-Kopman et al., "Clinical outcomes of indwelling pleural catheter-related pleural infections," Chest, vol. 144, no. 5, pp. 1597-1602, 2013.

[86] M. M. S. Lui, R. Thomas, and Y. C. Gary Lee, "Complications of indwelling pleural catheter use and their management," BMJ Open Respiratory Research, vol. 3, no. 1, Article ID e000123, 2016.

[87] J. M. Porcel, M. Torres, M. Pardina, C. Civit, A. Salud, and S. Bielsa, "Predictors of indwelling pleural catheter removal and infection: a single-center experience with 336 procedures," Journal of Bronchology \& Interventional Pulmonology, vol. 27, no. 2, pp. 86-94, 2020.

[88] A. O. Clive, H. Taylor, L. Dobson et al., "Prophylactic radiotherapy for the prevention of procedure-tract metastases after surgical and large-bore pleural procedures in malignant pleural mesothelioma (smart): a multicentre, open-label, phase 3, randomised controlled trial," The Lancet Oncology, vol. 17, no. 8, pp. 1094-1104, 2016.

[89] E. D. Penz, E. K. Mishra, H. E. Davies, B. J. Manns, R. F. Miller, and N. M. Rahman, "Comparing cost of indwelling pleural catheter vs talc pleurodesis for malignant pleural effusion," Chest, vol. 146, no. 4, pp. 991-1000, 2014.

[90] J. A. P. Olfert, E. D. Penz, B. J. Manns et al., "Cost-effectiveness of indwelling pleural catheter compared with talc in malignant pleural effusion," Respirology, vol. 22, no. 4, pp. 764-770, 2017.

[91] V. Puri, T. L. Pyrdeck, T. D. Crabtree et al., "Treatment of malignant pleural effusion: a cost-effectiveness analysis," The Annals of Thoracic Surgery, vol. 94, no. 2, pp. 374-380, 2012.

[92] R. Bhatnagar, E. K. Keenan, A. J. Morley et al., "Outpatient talc administration by indwelling pleural catheter for malignant effusion," The New England Journal of Medicine, vol. 378, no. 14, pp. 1313-1322, 2018.

[93] N. Qi, F. Li, X. Li et al., "Combination use of paclitaxel and avastin enhances treatment effect for the NSCLC patients with malignant pleural effusion," Medicine (Baltimore), vol. 95, no. 47, Article ID e5392, 2016.

[94] N. Du, X. Li, F. Li et al., "Intrapleural combination therapy with bevacizumab and cisplatin for non-small cell lung cancer-mediated malignant pleural effusion," Oncology Reports, vol. 29, no. 6, pp. 2332-2340, 2013.

[95] D. H. Sterman, E. Alley, J. P. Stevenson et al., "Pilot and feasibility trial evaluating immuno-gene therapy of malignant mesothelioma using intrapleural delivery of adenovirus-ifn $\alpha$ combined with chemotherapy," Clinical Cancer Research, vol. 22, no. 15, pp. 3791-3800, 2016.

[96] E. K. Mishra, A. O. Clive, G. H. Wills et al., "Randomized controlled trial of urokinase versus placebo for nondraining malignant pleural effusion," American Journal of Respiratory and Critical Care Medicine, vol. 197, no. 4, pp. 502-508, 2018.

[97] R. C. Rintoul, A. J. Ritchie, J. G. Edwards et al., "Efficacy and cost of video-assisted thoracoscopic partial pleurectomy versus talc pleurodesis in patients with malignant pleural mesothelioma (MesoVATS): an open-label, randomised, controlled trial," The Lancet, vol. 384, no. 9948, pp. 1118-1127, 2014.

[98] P. Sivakumar, A. Douiri, A. West et al., "OPTIMUM: a protocol for a multicentre randomised controlled trial comparing outpatient talc slurry via indwelling pleural catheter for malignant pleural effusion vs usual inpatient management," BMJ Open, vol. 6, no. 10, Article ID e012795, 2016.

[99] A clinical study evaluating the safety and effectiveness of a new pleural catheter for the medical management of symptomatic, recurrent, malignant pleural effusions compared to approved pleural catheter (SWIFT), ClinicalTrials.gov identifier.

[100] A randomised study of the relative benefits of combined indwelling pleural catheter (IPC) and talc pleurodesis therapy or video-assited thoracoscopic surgery (VATS) in the management of patients with malignant pleural effusion (AMPLE-3), Anzctr.org.au Identifier: ACTRN126180010 13257.

[101] C. Matthews, C. Freeman, L. D. Sharples et al., "MesoTRAP: a feasibility study that includes a pilot clinical trial comparing video-assisted thoracoscopic partial pleurectomy decortication with indwelling pleural catheter in patients with trapped lung due to malignant pleural mesothelioma designed to address recruitment and randomisation uncertainties and sample size requirements for a phase III trial," BMJ Open Respiratory Research, vol. 6, no. 1, Article ID e000368, 2019. 